Western North American Naturalist 68(3), (C) 2008, pp. 334-342

\title{
SEED GERMINATION OF THE INVASIVE PLANT BRASSICA TOURNEFORTII (SAHARA MUSTARD) IN THE MOJAVE DESERT
}

\author{
Dianne N. Bangle ${ }^{1}$, Lawrence R. Walker ${ }^{2}$, and Elizabeth Ann Powell ${ }^{3}$
}

\begin{abstract}
In the southwestern United States, Brassica tournefortii (Gouan) is a highly invasive plant that threatens native annuals. We conducted 5 experiments to help define the environmental limits for B. tournefortii germination. We found that this species germinates at a wide range of temperatures $\left(16^{\circ} \mathrm{C}\right.$ to $\left.32^{\circ} \mathrm{C}\right)$, under moderate salt concentrations (up to $3.20 \mathrm{dS} \cdot \mathrm{m}^{-1}$ ), in 24 hours of light or darkness, and after 10 weeks of submergence in water. These germination characteristics make $B$. tournefortii a potentially vigorous competitor of native annuals in the Mojave Desert. The fact that $B$. tournefortii can take advantage of and effectively reproduce in habitat altered by Tamarix spp. adds to management concerns for controlling this species. That $B$. tournefortii seeds remain viable after extended submergence, combined with our observation that $B$. tournefortii can float across large bodies of water with seed pods intact, indicates that this species is a highly successful invader and may be a threat to natural environments, including remote shoreline habitats. We can no longer assume that shoreline habitats experiencing little to no human contact will be safe from invasions initiated by humans.
\end{abstract}

Key words: Brassica tournefortii, seed germination, Sahara mustard, Mojave Desert, mucilaginous seed coat, invasive species, seed dispersal.

Brassica tournefortii (Gouan) is a winter annual native to arid deserts of North Africa and the Middle East (Minnich and Sanders 2000), as well as to the southern and eastern portion of the Mediterranean rim, where it thrives on marine beaches and sand dunes (Thanos et al. 1991). This species is considered weedy in its native environments (Narain and Prakash 1972, Prakash and Hinata 1980).

Considered an aggressively invasive weed of disturbed sites, beaches, and cultivated areas in southern Australia, B. tournefortii is capable of causing significant yield loss in crops, even when present at low densities (Chauhan et al. 2006). Brassica tournefortii biotypes (species sharing the same genotype) with resistance to the ALS inhibitor chlorosulfuron, which blocks amino acid synthesis, have been documented in Australia (Boutsalis et al. 1999, Chauhan et al. 2006). In North America, B. tournefortii occurs in Arizona, California, Nevada, New Mexico, Texas, and Utah. It has recently been listed as a noxious weed in Nevada and is one of the top nonnative plant concerns in deserts of the southwestern United States (U.S. Department of Agriculture 2005). Brassica tournefortii was first collected in North America in 1927 at Coachella in
Riverside County, California, and was presumably introduced with date palm shipments from the Middle East (Minnich and Sanders 2000). The specimen was incorrectly identified as $B$. arvensis until recently annotated to B. tournefortii (Minnich and Sanders 2000). In southern Nevada this species was first collected near Lake Mead National Recreation Area (LMNRA) in 1975 (Wesley E. Niles Herbarium), and subsequently it has spread into a variety of habitats, including sandy beaches, gravelly washes, roadsides, construction sites, and open deserts.

At LMNRA, B. tournefortii germinates in the late fall and early winter, after seasonal rains, and typically flowers and sets fruit by the end of March. This species establishes itself earlier in the spring season than most native annuals, which may contribute to its effectiveness as an invasive species in the southwestern United States. A similar phenomenon occurs in Australia, where B. tournefortii's early establishment affects cereal crop production (Moore and Williams 1983).

In some years annual populations of $B$. tournefortii are absent or scant, and in the following years there can be many plants, demonstrating the existence of a substantial seed

\footnotetext{
${ }^{1}$ Public Lands Institute, University of Nevada, Las Vegas, 4505 S. Maryland Parkway, Las Vegas, NV 89154-2040. E-mail: dianne.bangle@unlv.edu

${ }^{2}$ School of Life Sciences, University of Nevada, Las Vegas, 4505 S. Maryland Parkway, Las Vegas, NV 89154-4004.

${ }^{3}$ Box 61872, Boulder City, NV 89006-1872.
} 
bank (Montalvo et al. 2002). This pattern suggests that seeds may cycle through dormancy and conditional dormancy depending on environmental conditions. We have observed $B$. tournefortii following a boom-or-bust pattern in the Mojave Desert. Also, late winter or spring rains have resulted in a 2 nd generation (setting fruit in May) of germinants in a single season at LMNRA, a pattern described as typical of nonstrict (or facultative) winter annuals. Maintenance of dormancy and timing of germination are important phenological adaptations of weeds to their environment (Baskin and Baskin 1985).

At the end of the season, B. tournefortii plants can break off and tumble across the landscape, dispersing seeds along the way. Dispersal also occurs by rodent caching and perhaps by birds such as pigeons. Preliminary tests showed that B. tournefortii seeds are capable of germinating (in a drawer, on moist filter paper, and at room temperature) soon after maturing $(86 \%)$ and after 10 months of storage at room temperature (91\%). After collection at maturity, seeds from a closely related species, B. napus, germinated under laboratory conditions and were considered nondormant (Tokumasu and Kakihara 1990), as were the seeds of the related mustard species Arabidopsis thaliana (Baskin and Baskin 1971). When left in the field, winter annuals will typically disperse seeds in late spring or early summer and, in some cases, after temperatures have risen above those required for germination (Baskin and Baskin 2001). Brassica tournefortii may share this characteristic, as summer germination has not been observed at LMNRA even after summer rains.

Preliminary studies at LMNRA found that seeds survive submergence in tap water $(11 \%$ germination after 32 days submergence) and that $B$. tournefortii plants can produce $>10,000$ seeds per plant, occur in densities of 5 to 625 plants $\cdot \mathrm{m}^{-2}$, and grow taller than many native annuals (14 native annual species heights ranged from 9 to $30 \mathrm{~cm}$ while $B$. tournefortii height averaged $50 \mathrm{~cm}$ ). These preliminary data show B. tournefortii's capability of crowding and shading native annual species in the Mojave Desert. We suspect that the spread of B. tournefortii at LMNRA via water is significant: dried plants can float from beach to beach with seed pods still intact, and seedlings can become established along shorelines around the lake (D. Bangle personal observation).
In some areas B. tournefortii has begun to move from roadsides and beaches into the surrounding open desert. Because of this, it may be a direct threat to the U.S. native annual flora (U.S. Department of Agriculture 2005). Understanding how seeds are dispersed in a particular environment enables managers to make better informed decisions, especially when manpower and funding are limited. Our experiments were designed to increase understanding of B. tournefortii germination and to provide information that may be used to improve management decisions concerning this species. We measured seed viability, tolerance of submergence in water, and the effects of salinity, light, and temperature on germination.

\section{Methods}

\section{General Experimental Procedures}

Seeds of B. tournefortii were collected in southern Nevada during spring 2001 for a longevity experiment and in spring 2003 for the remaining experiments. Germination experiments began 5 months (2003 seed source) and 2.8 years (2001 seed source) after collection. Seeds were stored in a paper bag at room temperature. Unless otherwise noted, seeds were placed in petri dishes (50 seeds per dish; 3 dishes per experiment) on filter paper regularly moistened with deionized water, and dishes were kept in a drawer in a dark room (no natural or artificial light) at room temperature $\left(20^{\circ} \pm 1^{\circ} \mathrm{C}\right)$. While counting germinants, we briefly exposed petri dishes to minimal artifical light (except dishes in the dark experiment). All dishes were stacked singly or doubly, and their position in the drawer was rotated at random during the germination process. Seed germination (radicle protrusion) was monitored until germination ceased (3-12 days).

$$
\begin{gathered}
\text { Experiment 1: Viability/Storage } \\
\text { Temperatures }
\end{gathered}
$$

Seed viability was tested by measuring germination of seeds stored (dry, in petri dishes) at each of 6 temperatures $\left(-15^{\circ}, 5^{\circ}, 10^{\circ}, 25^{\circ}\right.$, $35^{\circ}$, and $45^{\circ} \mathrm{C}$ ). Each week for 10 weeks, 3 petri dishes were removed from each storage temperature for germination. We also measured long-term viability of seeds collected in 2001 (stored dry, at room temperature in unsealed manila envelopes for 2.8 years prior to germination test). 
Experiment 2: Submergence under Waters of Lake Mead

To test the effects of submergence in Lake Mead on B. tournefortii germination, we placed seeds in 30 eight-ounce water bottles $(50$ seeds per bottle). We covered the tops of the bottles with $10 \times 10-\mathrm{cm}$ mesh cloth squares (mesh opening: $0.5 \mathrm{~mm}$ ) to allow flow of lake water in and out of the bottles without losing seeds. The bottles were fastened to metal stakes, which were hammered into the lake bottom until the bottles were approximately $30 \mathrm{~cm}$ below the water surface. Every week for 10 weeks (week 7 was not tested), we removed 3 bottles and tested germination in the lab.

\section{Experiment 3: Salinity}

To test the effects of salinity on germination, we used a 2:1 molar solution of $\mathrm{NaCl}$ and $\mathrm{CaCl}_{2}$ chosen to represent the salts that may be present in the Lake Mead area (Barnes 2004, Walker et al. 2006). An initial solution of $13.2 \mathrm{dS} \cdot \mathrm{m}^{-1}$ (8448 ppm soluble salts) was diluted to 7 concentrations $\left(0.0498 \mathrm{dS} \cdot \mathrm{m}^{-1}\right.$ [32 ppm], $0.376 \mathrm{dS} \cdot \mathrm{m}^{-1}$ [241 ppm], $0.912 \mathrm{dS}$. $\mathrm{m}^{-1}$ [584 ppm], $1.58 \mathrm{dS} \cdot \mathrm{m}^{-1}$ [1011 ppm], 2.29 $\mathrm{dS} \cdot \mathrm{m}^{-1}$ [1466 ppm], $3.20 \mathrm{dS} \cdot \mathrm{m}^{-1}$ [2048 $\mathrm{ppm}$, and $6.66 \mathrm{dS} \cdot \mathrm{m}^{-1}$ [4262 $\left.\mathrm{ppm}\right]$ ), and 2 $\mathrm{mL}$ of each solution was added to designated petri dishes (3 per concentration for a total of 21 dishes). Additional solution (approximately $1 \mathrm{~mL}$ every other day) was added as necessary to keep the filter paper moist.

\section{Experiment 4: Germination Temperature Effects}

To test temperature effects on germination, we used filter paper kept moist at 10 temperatures $\left(5^{\circ}, 10^{\circ}, 16^{\circ}, 18^{\circ}, 20^{\circ}, 25^{\circ}, 28^{\circ}, 32^{\circ}, 35^{\circ}\right.$, and $40^{\circ} \mathrm{C}$ ) for 5 days. Glass petri dishes were used for the $35^{\circ} \mathrm{C}$ and $40^{\circ} \mathrm{C}$ tests.

\section{Experiment 5: Light/Dark Germination}

To test the effects of light/dark conditions on germination, we conducted 4 tests. Six petri dishes with 50 seeds each were prepared in low-light conditions using filter paper and 3 $\mathrm{mL}$ of deionized water. Once the water was added, each dish was immediately wrapped in aluminum foil, placed in a drawer, and kept at room temperature. Two dishes were removed on each consecutive day for 3 days and discarded after germinants were counted.
Light tolerance in B. tournefortii was tested using 3 different light conditions. During the following light experiments, we did not isolate specific wavelength regions or control for temperature. Photosynthetic photon flux (PPF) was measured (using a Spectrum Technologies, Inc., model BQM quantum light meter), as was temperature (using a HOBO H8 Pro Series logger) at seed level. In test 1, a Phillips 15watt grow light and a 60-watt incandescent bulb were used (PPF measured $127 \mu \mathrm{mol}$. $\mathrm{m}^{-2} \mathrm{~s}^{-1}$, temperature $30^{\circ} \mathrm{C}$ ) in 24 -hour light conditions.

In the 2nd light experiment, we used a 15watt General Electric warm white florescent bulb, as well as a 60-watt incandescent bulb, in 24-hour light conditions. In this test, PPF measured $52 \mu \mathrm{mol} \cdot \mathrm{m}^{-2} \mathrm{~s}^{-1}$ and the temperature was $27^{\circ} \mathrm{C}$.

In the 3rd light experiment, a Phillips natural-light florescent bulb, which emitted the full spectrum of natural daylight, was used (no incandescent bulb) in 24-hour light conditions. The PPF in this test measured $20 \mu \mathrm{mol}$ $\mathrm{m}^{-2} \mathrm{~S}^{-1}$ and the temperature was $25^{\circ} \mathrm{C}$.

\section{Statistical Analyses}

Statistical analyses were performed with the software SAS JMP (SAS Institute 2002). We used a 1-way ANOVA to compare means in all experiments except experiment 1 , where we used a 2 -factor factorial design consisting of 6 temperature levels $\left(-15^{\circ}, 5^{\circ}, 10^{\circ}, 25^{\circ}, 35^{\circ}\right.$, and $45^{\circ} \mathrm{C}$ ) and 10 storage levels (1-10 weeks). For mean separation, we used Tukey's test with $\alpha=0.05$. Data for all experiments, except experiment 2, approximated equal variance (Levene's test) and normality assumptions (Shapiro-Wilk test). In experiment 2, when we tested arcsine and square-root transformation, the variance remained unequal, so we ran a Welch ANOVA. Results were consistent with the traditional ANOVA. In this paper we report traditional ANOVA results for all experiments.

\section{Results}

Germination of B. tournefortii under standard conditions (deionized water, room temperature) was complete within 4 days. Experiments 2 and 3 showed delayed germination with completion at 12 and 8 days, respectively. 
TABLE 1. Comparison of viability of Brassica tournefortii seeds (collected at Lake Mead National Recreation Area, Mojave Desert) at varying storage temperatures $(\bar{x} \pm s, n=3)$. Seeds were stored from 1 to 10 weeks at a range of temperatures $\left(-15^{\circ}, 5^{\circ}, 10^{\circ}, 25^{\circ}, 35^{\circ}\right.$, and $\left.45^{\circ} \mathrm{C}\right)$ before removal and placement in a drawer at room temperature for germination. Germination ceased after 3 days. ND = no data.

\begin{tabular}{lcccccr}
\hline & \multicolumn{5}{c}{ Temperature $\left({ }^{\circ} \mathrm{C}\right)$} \\
\cline { 2 - 6 } Week & -15 & 5 & 10 & 25 & 35 & 45 \\
\hline 1 & $98 \pm 2$ & $94 \pm 3$ & $95 \pm 5$ & $95 \pm 3$ & $99 \pm 1$ & $97 \pm 4$ \\
2 & $97 \pm 3$ & $95 \pm 4$ & $97 \pm 1$ & $97 \pm 1$ & $99 \pm 1$ & $97 \pm 1$ \\
3 & $97 \pm 3$ & $96 \pm 3$ & $94 \pm 2$ & $99 \pm 1$ & $99 \pm 1$ & $99 \pm 2$ \\
4 & $97 \pm 1$ & $91 \pm 1$ & $98 \pm 0$ & $99 \pm 1$ & $97 \pm 4$ & $99 \pm 2$ \\
5 & $94 \pm 3$ & $99 \pm 1$ & $99 \pm 1$ & $96 \pm 4$ & $99 \pm 1$ & $97 \pm 3$ \\
6 & $99 \pm 1$ & $98 \pm 3$ & $100 \pm 0$ & $98 \pm 3$ & $98 \pm 2$ & $98 \pm 3$ \\
7 & $99 \pm 1$ & $95 \pm 3$ & $95 \pm 5$ & $95 \pm 5$ & $99 \pm 1$ & $98 \pm 2$ \\
8 & ND & $99 \pm 1$ & $96 \pm 3$ & $99 \pm 1$ & $97 \pm 3$ & $99 \pm 2$ \\
9 & $96 \pm 4$ & $93 \pm 1$ & $94 \pm 2$ & $96 \pm 2$ & $96 \pm 0$ & $95 \pm 1$ \\
10 & $99 \pm 1$ & $93 \pm 2$ & $97 \pm 3$ & $96 \pm 0$ & $98 \pm 3$ & $99 \pm 1$ \\
\hline
\end{tabular}

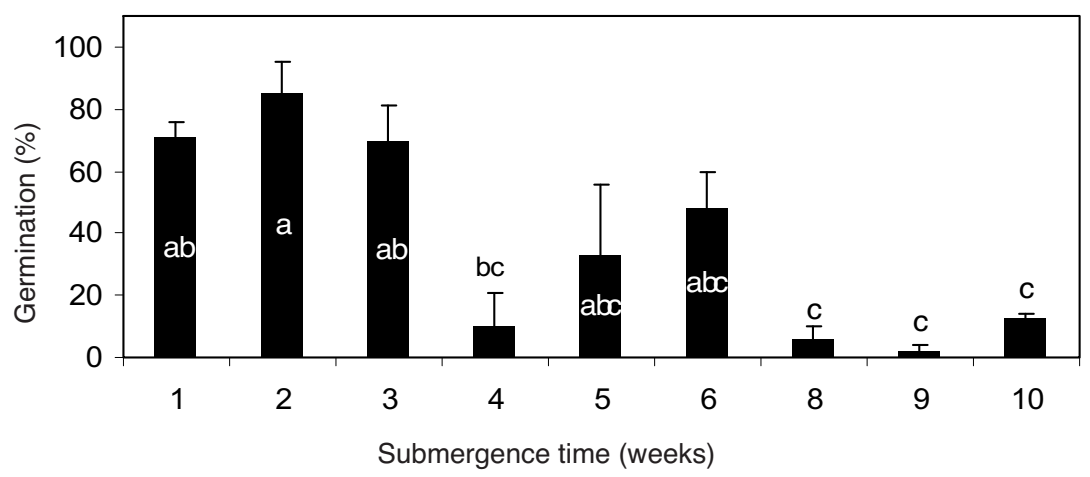

Fig. 1. Mean germination percentages $(n=3)$ for Brassica tournefortii seeds after submergence at Lake Mead National Recreation Area. Seeds were germinated in a drawer in a dark room at room temperature $\left(20^{\circ} \pm 1^{\circ} \mathrm{C}\right)$. Petri dishes were briefly exposed to artificial light while germinants were counted. Germination ceased after 12 days. Bars represent 1 standard deviation. Means with the same letter do not differ $(P>0.05)$.

\section{Experiment 1: Viability/Storage Temperatures}

Main effects were significant for week $(F=$ 2.72, $P=0.0064)$ and temperature $(F=4.85$, $P=0.0004)$, and they did not interact $(F=$ $1.40, P=0.0767)$. The range of percent germination across all treatment combinations was 91\%-100\% (Table 1). Germination of B. tournefortii seeds from the 2001 seed source stored at room temperature was $99.3 \%$ after 3 days. Thus, no loss in germinability occurred during nearly 3 years of shelf storage.

Experiment 2: Submergence under Waters of Lake Mead

One-way ANOVA was significant $(F=$ $6.60, P=0.0004)$, with $>70 \%$ of $B$. tournefortii seeds viable for the first 3 weeks of submer- gence in Lake Mead. Viability gradually declined to $<10 \%$ after $8-10$ weeks of submergence (Fig. 1). Week-4 bottles had a significant amount of algae in them, which may have affected germination (2 petri dishes had $0 \%$, and the 3rd had 38\% germination; seeds molded quickly).

\section{Experiment 3: Salinity}

Germination decreased as soil salinity increased $(P<0.0001$; Fig. 2$)$, with minimal germination at $3.2 \mathrm{dS} \cdot \mathrm{m}^{-1}(2 \%)$ and no germination at $6.66 \mathrm{dS} \cdot \mathrm{m}^{-1}$.

\section{Experiment 4: Germination Temperature Effects}

Germination occurred between $16^{\circ}$ and $32^{\circ} \mathrm{C}$ but not at $5^{\circ}, 10^{\circ}, 35^{\circ}$, or $40^{\circ} \mathrm{C}(P<0.0001$; Fig. 3). Highest germination occurred at $16^{\circ}$ to 


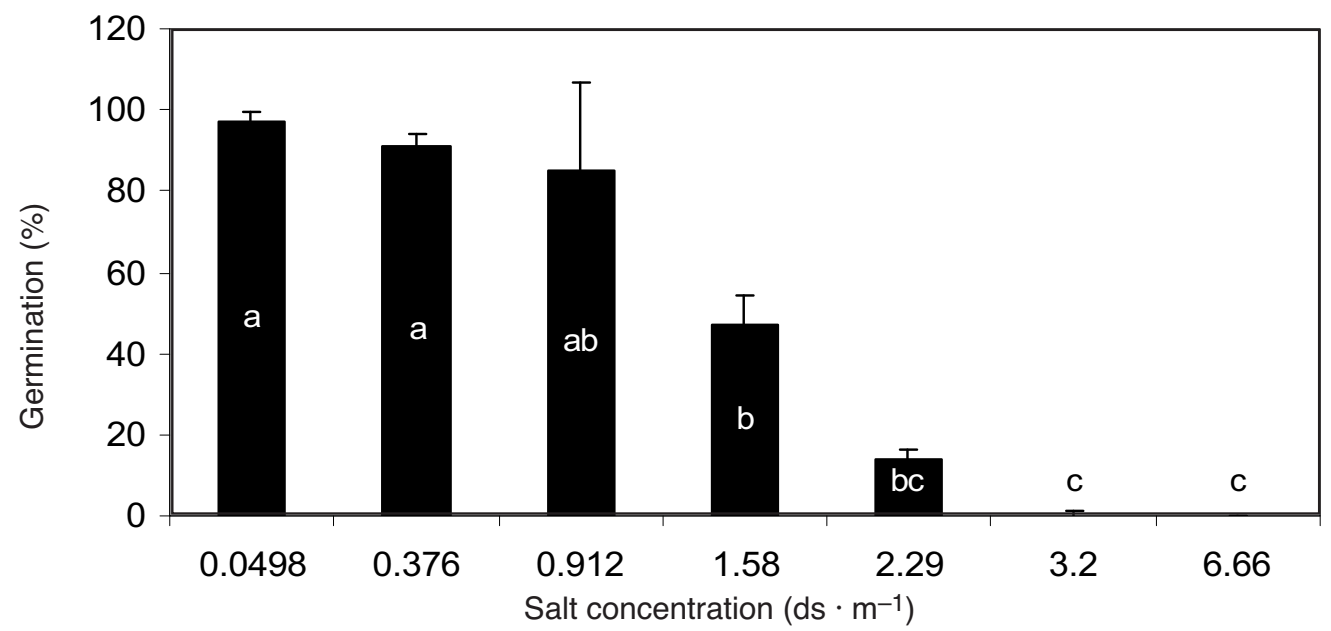

Fig. 2. Mean germination percentages $(n=3)$ for Brassica tournefortii seeds at varying $\mathrm{NaCl}: \mathrm{CaCl}_{2} 2: 1$ molar concentrations. Seeds were germinated in a drawer in a dark room at room temperature $\left(20^{\circ} \pm 1^{\circ} \mathrm{C}\right)$. Petri dishes were briefly exposed to artificial light while germinants were counted. Germination ceased after 8 days. Bars represent 1 standard error. Means with the same letter do not differ $(\mathrm{P}>0.05)$.

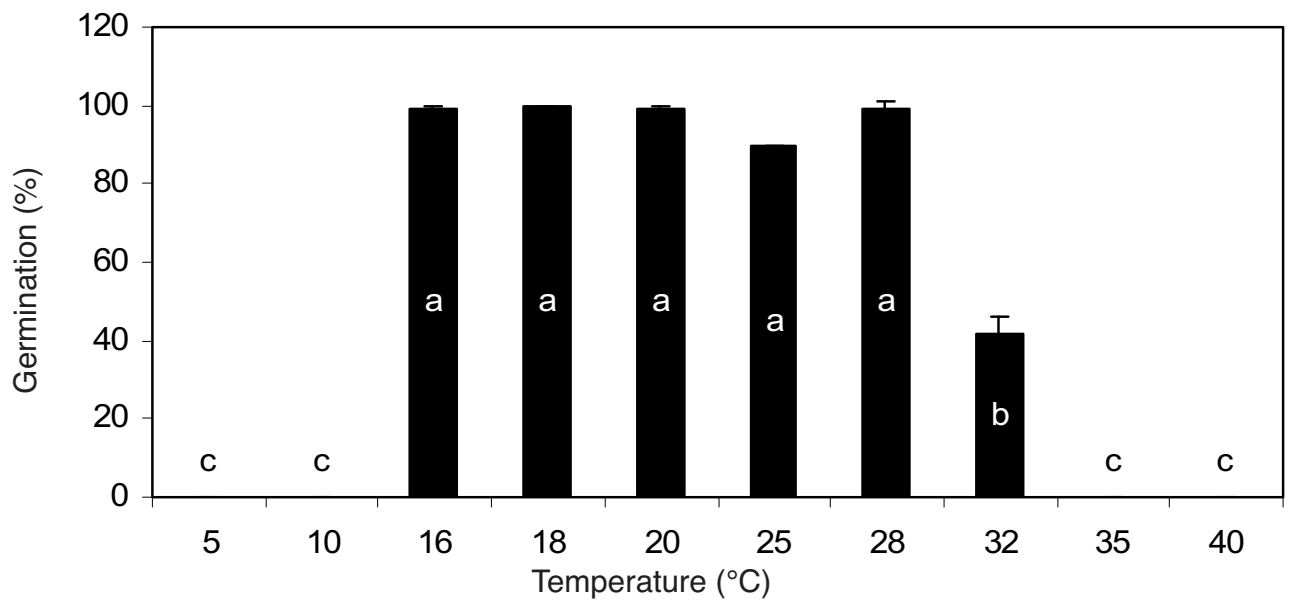

Fig. 3. Mean germination percentages $(n=3)$ for Brassica tournefortii seeds at varying germination temperatures. Seeds were germinated in a drawer in a dark room at room temperature $\left(20^{\circ} \pm 1^{\circ} \mathrm{C}\right)$. Petri dishes were briefly exposed to artificial light while germinants were counted. Germination ceased after 2-6 days. Bars represent 1 standard error. Means with the same letter do not differ $(\mathrm{P}>0.05)$.

$28^{\circ} \mathrm{C}(95-100 \% \pm 4 \%)$; at $32^{\circ} \mathrm{C}$ germination dropped to $42 \% \pm 7 \%$.

\section{Experiment 5: Light/Dark Germination}

Main effects were significant for light and dark germination $(F=52.1, P=0.0001)$, with dark germination at $95 \% \pm 1 \%$ and germination under 3 light conditions (PPF at 127 , 52 , and $20 \mu \mathrm{mol} \cdot \mathrm{m}^{-2} \mathrm{~s}^{-1}$ ) at $87 \% \pm 2 \%, 85 \% \pm$ $10 \%$, and $31 \% \pm 8 \%$, respectively.

\section{Discussion}

Invasive plant species compete with native plants for nutrients, water, and sunlight. Based on characteristics such as high seed output, high and efficient seed dispersal, early phenology, and rapid growth rate (Rao 2000), B. tournefortii is a successful invader of the Mojave Desert. Our results suggest several possible mechanisms to explain the rapid expansion of 
B. tournefortii in the Mojave Desert. Effective dispersal techniques are key attributes that ensure a plant species' success. Seeds of many weed species (including B. tournefortii), when imbibed, have a mucilaginous seed coat, which aids in dispersal (Young and Evans 1973) or can physically act as an oxygen and water barrier, thus delaying germination until conditions are suitable (Witztum et al. 1969). A mucilaginous seed coat appears to be key to the spread of B. tournefortii along the shoreline and in other areas around LMNRA. The imbibed seeds stick to tires, shoes, boats, and the plant itself. Wind patterns, combined with a nearby water body (Lake Mead), appear to have influenced dispersal of $B$. tournefortii, as senesced plants (seeds intact) have been observed floating across Lake Mead (D. Bangle personal observation). Our study provides evidence that $B$. tournefortii seeds can survive in Lake Mead with significant germination after 6 weeks of submergence (Fig. 1), allowing enough time for $B$. tournefortii plants to disperse to other shoreline areas while floating with the currents.

Brassica tournefortii did not show a decline in germinability over the time period tested or under varying storage temperatures. These data show no meaningful differences in actual averages, so it is unclear whether statistical results have practical significance. Brassica tournefortii seeds can remain viable in dry storage, showing no sign of decline in germination after nearly 3 years. Long-term seed burial studies are needed to determine the age-viability relationship of $B$. tournefortii seeds in the natural environment. A study on seed longevity in B. napus found that seeds remain viable in the soil for 5-10 years (Schlink 1998, Lutman et al. 2003). Studies by Chauhan et al. (2006) and Mohler and Galford (1997) found that germination of B. tournefortii and B. napus seeds located at the surface are susceptible to loss from germination or desiccation relatively quickly, while seeds located deeper in the soil (via tilling or disturbance) remain viable longer, suggesting that near-surface conditions are more suitable for germination, pathogenic attack, and granivory.

Seeds of some winter annuals are physiologically ready to germinate at any time of year if proper temperature and moisture conditions are provided (Baskin and Baskin 2001). Germination of $B$. tournefortii under constant tem- peratures in the lab occurred between $16^{\circ}$ and $32^{\circ} \mathrm{C}$. Thanos et al. (1991) found an even wider range of germination temperatures $\left(10^{\circ}-30^{\circ} \mathrm{C}\right)$ for B. tournefortii growing in Greece, but optimum germination temperatures were very similar between that study and ours. The lack of germination at lower temperatures in our study may be the result of differences in experimental design or among genetic variants of $B$. tournefortii from various geographic locations.

At LMNRA we have observed a 2nd-generation germination event occurring in the early spring, which suggests that at least a portion of freshly matured $B$. tournefortii seeds do not experience primary dormancy, and those that do not may germinate in the field soon after ripening, if conditions are suitable. Equally, a 2nd-germination event in the spring from the existing seed bank is not uncommon for facultative winter annuals (Baskin and Baskin 1971, 2001). It appears that temperature may be the overriding factor controlling germination of $B$. tournefortii within the Mojave Desert during mid- and late summer. This limiting factor is also found in other winter annuals that shed their seeds in spring (Baskin and Baskin 1971).

Significant germination under dark conditions at optimal temperatures $\left(20^{\circ} \mathrm{C}\right)$ was found in the current study, as well as in studies by Delipetrou et al. (1993) and Thanos et al. (1991). Light-sensitivity results differed between Delipetrou et al. (1993), Thanos et al. (1991), Chauhan et al. (2006), and our study. Chauhan et al. (2006) showed results comparable to our 3rd light test under similar temperature conditions $\left(20^{\circ}-25^{\circ} \mathrm{C}\right)$, but found that $B$. tournefortii seeds were inhibited by light at suboptimal temperatures. Thanos et al. (1991) and Delipetrou et al. (1993) studied photoinhibition of seed germination $\left(20 / 13^{\circ} \mathrm{C}\right.$ and $20^{\circ} \mathrm{C}$, respectively) and found minimal or total inhibition (10\% and $0 \%$, respectively). Differing results between studies may be from differences in experimental design, length of afterripening of seeds used in each experiment, or different genetic variants between regions. In the current study, the differences in results between the 3 tested light conditions cannot be fully explained based on limitations in experimental design. We can say, however, that the spectrum of light and the location of the most intense peaks were different in the first 2 experiments compared to the 3rd. A grow light (used in light experiment 1) and a warm white 
light (used in light experiment 2) show strong peaks in the blue and red portions of the spectrum, and an incandescent bulb showed peaks in the red and far-red portion. The 3rd light experiment using only a natural light, which does not emit strong peaks in the red region of the spectrum, showed a decrease in germination compared to the first 2 tests. Absorption of red light is known to promote germination in some species (Baskin and Baskin 2001). The difference in red light intensity between experiments may have caused the decrease in germination, but overall our results do not support other studies that show complete photoinhibition of seed germination in B. tournefortii. It is possible that in different environments different germination responses prevail, or that a subset of responses is rare in natural populations (contrary to their detection in laboratory settings) and that variation in the species is more important for long-term evolutionary potential than for short-term ecological flexibility (Mathews 2006). A more controlled study evaluating light sensitivity in B. tournefortii seed from the Mojave Desert is needed.

Brassica tournefortii thrives on marine beaches in its native habitat, suggesting that it likely has a higher tolerance for saline soils than other desert annuals do. Support for this idea stems from observations that B. tournefortii is found not only on a range of substrate types but also in the leaf litter of Tamarix ramosissima. The invasive species $T$. ramosissima and T. aphylla are established along the shoreline and water courses surrounding LMNRA and can alter soil chemistry by increasing salinity levels (Walker and Smith 1997, Di Tomaso 1998, Walker et al. 2006). Walker et al. (2006) and Barnes (2004) tested effects of soil salinity on seed germination in T. aphylla and found that germination occurred under low salt concentration $(18 \%$ at $1.85 \mathrm{dS}$. $\mathrm{m}^{-1}$ [1184 ppm]; $\mathrm{NaCl} / \mathrm{CaCl}_{2}$ 2:1 molar solution), comparable to germination of $B$. tournefortii, which showed similar results at a higher concentration $\left(18 \%\right.$ at $2.29 \mathrm{dS} \cdot \mathrm{m}^{-1}[1466$ ppm], $\mathrm{NaCl} / \mathrm{CaCl}_{2}$ 2:1 molar solution). Chauhan et al. (2006) tested the effects of soil salinity on B. tournefortii and found that under dark conditions, $18 \%$ of seeds germinated at $160 \mathrm{mM}$ (9344 ppm) NaCl. They also found significantly less germination when experiments were conducted under light/dark conditions (almost complete inhibition at $80 \mathrm{mM}[4672$ ppm] $\mathrm{NaCl}$ ). Salinity tolerance, as it affects germination in the related species B. napus, was tested at varying salt concentrations $\left(\mathrm{NaCl} / \mathrm{CaCl}_{2}\right.$ 2:1 molar solution) in combination with various temperatures (Puppala et al. 1999). Results showed $28 \%$ germination in the $15^{\circ}-25^{\circ} \mathrm{C}$ range at salinity levels as high as $21.6 \mathrm{dS} \cdot \mathrm{m}^{-1}$.

We have noted that $B$. tournefortii displays patterns of boom-or-bust years typical of annual plant populations, demonstrating the potential existence of a substantial seed bank. When a substantial seed bank exists, seeds may cycle through different stages of dormancy, depending on environmental conditions. Because maintenance of dormancy and timing of germination are important phenological adaptations of weeds to their environment, the annual dormancy cycle is a critical component of predictive models for weed pest management (Baskin and Baskin 1985). Research on dormancy cycles of B. tournefortii is needed to assist land managers in controlling this species under unpredictable climatic conditions such as those experienced in the Mojave Desert.

\section{Conclusions}

Brassica tournefortii may pose a considerable threat to native annuals because of its early seedling emergence combined with an ability to germinate in moderately saline soils, at a wide range of temperatures, after extended storage, and after extended submergence. Salinity tolerance can be an important characteristic of an invasive plant species, enabling it to take advantage of open niches. The ability of B. tournefortii to take advantage of and effectively reproduce in habitats altered by Tamarix spp., as well as in other naturally occurring saline habitats, adds to management concerns for controlling this species. Control efforts for B. tournefortii appear to be most efficient early in establishment while plants are still in the rosette stage and can simply be uprooted without the need for time-consuming bagging and removal. Ideally, land managers in the Mojave Desert should initiate surveys for B. tournefortii soon after rainfall events (occurring at temperatures between $16^{\circ}$ and $32^{\circ} \mathrm{C}$ ). At Lake Mead NRA, managers armed with the knowledge that B. tournefortii seeds can survive submergence for several weeks and that senesced plants can disperse 
to other shoreline areas (previously isolated from direct contact with $B$. tournefortii infestations) can increase the effectiveness of their control efforts by concentrating on eradicating plants in areas that act as vectors to uninfested areas. This information may be vital to land managers in other areas of the country who deal with invasive species that form mucilaginous seed coats such as B. tournefortii does. Understanding dispersal mechanisms in a particular environment enables managers to make better informed decisions concerning control efforts.

Studies of the principles of environmental control of germination may aid in the interpretation and, if possible, prediction of the field behavior of troublesome weeds (Baskin and Baskin 1985). Understanding specific requirements of $B$. tournefortii can help managers prepare control efforts each year in an adaptive management style. By addressing some of the gaps in our knowledge of the physiological limitations of $B$. tournefortii seeds in the Mojave Desert, this study allows managers to employ more effective management techniques and provides baseline information for use in demographic models. Further research is needed on seed longevity in the soil, herbicide effectiveness, resource use, reproductive biology, competition with native species, and annual dormancy cycles, including confirmation of primary dormancy, in order to make appropriate weed control decisions concerning $B$. tournefortii in the southwestern United States.

\section{ACKNOWLEDGMENTS}

We thank Scott Abella at the Public Lands Institute (University of Nevada, Las Vegas) for providing statistical advice and a review of the manuscript, Jeff Holland for laboratory assistance, and 2 anonymous reviewers for reviewing the manuscript. We also thank the National Park Service at Lake Mead National Recreation Area for their cooperation and for the use of NPS land throughout the submergence test.

\section{Literature Cited}

BARnES, P.L. 2004. Tamarix aphylla: a newly invasive tree in southern Nevada. Master's thesis, Department of Biological Sciences, University of Nevada, Las Vegas.

Baskin, C.C., AND J.M. Baskin. 2001. Seeds: ecology, biogeography, and evolution of dormancy and germination. Academic Press, London.
Baskin, J.M., AND C.C. BASKIN. 1971. Germination of winter annuals in July and survival of the seedlings. Bulletin of the Torrey Botanical Club 98:272-285.

. 1985. The annual dormancy cycle in buried weed seeds: a continuum. BioScience 35:492-498.

Boutsalis, P., J. Karotam, and S.B. Powles. 1999. Molecular basis of resistance to acetolactate synthaseinhibiting herbicides in Sisymbrium orientale and Brassica tournefortii. Pesticide Science 55:507-516.

Chauhan, B.S., G. Gill, and C. Preston. 2006. African mustard (Brassica tournefortii) germination in southern Australia. Weed Science 54:891-897.

Delipetrou, P., K. Georghiou, and C. Thanos. 1993. On the photoinhibition of seed germination in the maritime plant Brassica tournefortii. Fourth International Workshop on Seeds: Basic and Applied Aspects of Seed Biology 2:473-478.

Di Tomaso, J. 1998. Impact, biology and ecology of salt cedar in the southwestern United States. Weed Technology 12:326-336.

Lutman, P.J.W., S.E. Freeman, and C. Pekrun. 2003. The long-term persistence of seeds of oilseed rape (Brassica napus) in arable fields. Journal of Agricultural Science 141:231-240.

Mathews, S. 2006. Phytochrome-mediated development in land plants: red light sensing evolves to meet the challenges of changing light environments. Molecular Ecology 15:3483-3503.

MinniCH, R.A., AND A.C. SANDERs. 2000. Brassica tournefortii. In: C.C. Bossard, J.M. Randall, and M.C. Hoshovsky, editors, Invasive plants of California's wildlands. University of California Press, Berkeley.

Mohler, C.L., AND A.E. GaLford. 1997. Weed seedling emergence and seedling survival: separating the effects of seed position and soil modification by tillage. Weed Research 37:147-155.

Montalvo, Q.A.M., L.J. Feist-Alvey, and C.E. Koehler. 2002. The effect of fire and cold treatments on seed germination of annual and perennial populations of Eschscholzia californica (Papaveraceae) in southern California. Madroño 49:207-227.

Moore, R.M., and J.D. Williams. 1983. Competition among weedy species: diallel experiments. Australian Journal of Agriculture 34:119-131.

Narain, A., AND S. PraKash. 1972. Investigations on the artificial synthesis of amphidiploids of Brassica tournefortii Gouan with the other elementary species of Brassica. I. Genomic relationships. Genetica 43:90-97.

PraKash, S., AND K. Hinata. 1980. Taxonomy, cytogenetics and origin of crop Brassica, a review. Opera Botanica. International Monograph Series 55.

Puppala, N., J.L. Fowler, L. Poindexter, and H.L. BHARDWAJ. 1999. Evaluation of salinity tolerance of canola germination. In: J. Janick, editor, Perspectives on new crops and uses. Alexandria, VA.

RAO, V.S. 2000. Principles of weed science. 2nd edition. Science Publishers, Inc. Enfield, NH.

SAS Institute, InC. 2002. JMP. Version 5. User's guide. SAS Institute, Inc., Cary, NC. 263 pp.

SCHLINK S. 1998. 10 years survival of rape seed (Brassica napus L.) in soil. Journal of Plant Diseases Protection, Special Issue 16:169-172.

Thanos, C.A., K. Georghiou, D.J. Douma, and C.J. Marangaki. 1991. Photoinhibition of seed germination in Mediterranean maritime plants. Annals of Botany 68:469-475. 
Tokumasu, S., and F. KaKinara. 1990. Seasonal germination periodicity of imbibed dormant seeds of rape (Brassica napus L.). Scientia Horticulturae 42:1-7.

United States Department of Agriculture. 2005. Noxious weed list. University of California Press, Berkeley. 1400 pp.

Walker, L.R., P.L. Barnes, And E.A. Powell. 2006 Tamarix aphylla: a newly invasive tree in southern Nevada. Western North American Naturalist 66: 191-201.

WALKER, L.R., AND S. SMITH. 1997. Impacts of invasive plants on community and ecosystem properties. In: J.O. Luken and J.W. Thieret, editors, Assessment and management of plant invasions. Springer-Verlag, New York.
Wesley E. Niles Herbarium Database. School of Life Sciences, University of Nevada, Las Vegas, Box 454004, Las Vegas, NV 89154-4004.

Witztum, A., Y. Gutterman, and M. Evenari. 1969. Integumentary mucilage as an oxygen barrier during germination of Blepharis persica (Burm) Kuntze. Botanical Gazette 130:238-241.

Young, J.A., And R.A. Evans. 1973. Mucilaginous seed coats. Weed Science 21:52-54.

Received 8 June 2007 Accepted 5 March 2008 